\title{
A POLÍTICA COMO SUPERAÇÃO E ORDENAMENTO DA VIOLÊNCIA PELA NEGOCIAÇÃO
}

\author{
Entrevista com Tullo Vigevani ${ }^{1}$
}

\section{Revista Malala (RM)}

Muito obrigada pelo aceite para essa entrevista.

A primeira pergunta que gostaríamos de fazer é um pouco ampla e mais teórica. Quando se pensa sobre violência na política internacional, esse é um tema que está sempre presente? Quando se estuda a política internacional, é preciso sempre considerar a violência como um tema inevitável? Porque se fossemos lembrar, por exemplo, da Guerra-Fria, tinhase aquele temor de uma guerra nuclear, então, as pessoas construíam aqueles abrigos antinucleares, os lugares tinham referências sobre como fugir em caso de um ataque nuclear. Tínhamos uma estabilidade com esse medo de um conflito nuclear. Hoje em dia nós não temos mais a Guerra-Fria, não se tem essa configuração de bipolaridade. Mas nós temos, por exemplo, essa ameaça terrorista, e de certa forma, também, o tempo todo as pessoas estão com medo de atentados terroristas. Que podem ser nos aeroportos, shopping centers, transportes públicos, etc. Parece que a ordem mudou, mas o fator medo e violência continuam presentes. Como o senhor enxerga essa relação entre a ordem internacional, a política internacional e a presença/persistência da violência?

\section{Tullo Vigevani (TV)}

Essa pergunta obviamente exige uma resposta muito ampla, que é difícil de ser resumida em um único comentário pontual. Existe uma infinidade de livros e textos de discussões sobre a questão da violência, desde épocas muito remotas até hoje. Na própria Bíblia fala-se muito em violência e em guerras. Eu diria, para simplificar e dar uma resposta concentrada, que o estado de violência é um estado que tem acompanhado a humanidade desde seus primeiros momentos. Na teoria política clássica o tema é essencial, pensemos em autores como Maquiavel, Hobbes, ou mesmo, de outro lado, em autores como Locke e Rousseau. Para alguns, a política também tem o papel de organizar, de ordenar a violência, de hierarquizá-la. É muito conhecida a definição de Weber sobre o Estado como detentor do uso legítimo da violência. Portanto, ela é parte da ordem política e da ordem social. Sobre quais sejam as razões da violência também há muitas explicações. Alguns atribuem

\footnotetext{
${ }^{1}$ Entrevista realizada por Ariel Finguerut e Natalia Nahas Calfat (membros do conselho editorial da Revista Malala e pesquisadores do GTOMMM), em 30 de junho de 2016 na UNESP. Agradecemos o auxílio e contribuições de Cila Lima na transcrição e revisão desta entrevista, também membro do conselho editorial da Revista Malala e pesquisadora do GTOMMM. Versão revista pelo professor Tullo Vigevani em 17 de setembro/2016.
} 


\section{entrevista}

à própria natureza do homem, como faz o jus naturalismo. Outros como Rousseau, por exemplo, a atribuem à organização social. Outros, sobretudo na vertente marxista, atribuem a violência às estruturas de classes, às desigualdades e à propriedade. Isto claro, em termos gerais.

No que se refere à violência contemporânea, não estou totalmente de acordo com a visão de que as relações tensas entre os Estados tenham desaparecido. Elas continuam existindo, de outras formas, provavelmente, mas continuam existindo e persiste a tendência dos Estados, na medida de suas capacidades, à expansão, à utilização do próprio poder; e, há a tendência - que foi muito importante no debate de Relações Internacionais no período pós-segunda guerra mundial - à contenção. A contenção é uma política que muitos Estados exercem. Os Estados Unidos a utilizam, os Estados da União Europeia usam essa política, a Rússia também, assim como a China. Outros Estados - de menor peso atualmente no sistema internacional - também buscam usar essa política, ainda que seja em termos locais ou regionais nas suas zonas de influência. Portanto, as tensões internacionais existem e não acabaram. Certamente o mundo contemporâneo vive um tempo longo sem guerras gerais, mundiais, desde 1945, ou seja, há mais de setenta anos. Mas isso tampouco é novo. O Concerto Europeu, com regras e procedimentos imprecisos, como analisou Holsti, garantiu a ordem internacional das grandes potências europeia por cem anos, de 1815 a 1914.

Mas o núcleo da pergunta de vocês é o porquê da violência do terrorismo, o porquê da violência de grupos. Eu daria uma resposta geral para o tema, que obviamente teria que ser melhor analisado, melhor examinado em seus detalhes e em suas profundas diferenças. A violência, em qualquer caso, tem origens, não nasce por acaso, tão pouco é um fato que tem origens apenas culturais. Vou dar alguns exemplos. O Nazismo, que foi um regime que exerceu em formas quase evidentes, quase transparentes, o poder de modo violento, também tem origens explicáveis. Há uma imensa literatura que estuda seus pressupostos culturais, sociais, nas relações de produção, nas relações de classe e, provavelmente, acima de tudo, nas Relações Internacionais. Lembrem-se que tanto Lênin quanto Trotsky, quanto Wilson e Keynes perceberam muito bem os riscos que trariam os diktats de Versalhes de 1919, entre eles as indenizações que a Alemanha teria que pagar, depois da Primeira Guerra Mundial. Isso não foi uma invenção do nazismo, trata-se de fatos hoje amplamente reconhecidos. Sabemos a influência que tiveram no desencadeamento do nazismo. Certamente, entender como causas objetivas e até injustiças provocam a violência, implica o exame das circunstâncias particulares em que os fatos são gerados. Achcar (Gilbert) afirma que, diferentemente do que se tornou um senso comum, a violência praticada por alguns segmentos de populações árabes e/ou muçulmanas não tem uma origem especificamente cultural. A origem da violência encontra-se no sentimento de injustiça que essas mesmas populações sofreram ao longo da história, acúmulo de frustrações. Algumas delas não imediatas, mas resultantes de narrativas que se reproduzem ao longo do tempo. As manifestações são de tipos distintos, inclusive, porque as circunstâncias em 
que estes povos se encontravam ou se encontram hoje são muito diferentes. Mas as raízes da violência devem ser buscadas em razões materiais, afirma Achcar. Apenas para lembrar, o chinês da literatura colonial é apresentado como preguiçoso, quem o descreveria como tal no século XXI?

Não sou especialista no tema de terrorismo, portanto não poderia afirmar que apenas razões materiais expliquem tudo, mas parece que é uma linha de investigação que efetivamente deve ser bem considerada. Razões materiais não compõem apenas razões econômicas, mas, também, razões históricas, temporais, culturais. No caso do Oriente Médio há muitos tipos de violências internas às populações árabes e muçulmanas, mas, também há outras externas. Nos Estados Unidos há no debate intelectual um crescente reconhecimento de que a Guerra ao Terror aumentou a instabilidade, sendo origem de novas gerações de violência. Ainda que também exigindo melhor precisão de análise, não seria historicamente adequado desconhecer o fato de que o deslocamento da população árabe-palestina em 1948, mas, sobretudo, a permanência da ocupação dos Territórios a partir de 1967, acabou por também produzir confrontos políticos, assim como ações violentas. Do mesmo modo, há formas de ação violenta por parte de Israel (ainda que exercida pelo Estado e não por grupos não estatais). Para explicar a violência do Estado de Israel, também se pode usar a mesma diretriz das razões objetivas, materiais e etc. Há muitos estudos sobre o tema. Na literatura de Relações Internacionais é muito valorizada a ideia da sensação de insegurança que os Estados e as sociedades vivem (seja por razões objetivas ou por razões subjetivas). Sensação que acaba por produzir resultados que criam situações de violência efetiva ou situações de injustiças para outros que estão envolvidos no mesmo processo.

\section{RM}

Tullo, o senhor mencionou vários aspectos relacionados à violência: a natureza humana, as injustiças, também as estratégias que os Estados usam para lidar com essa violência. $\mathrm{E}$ como é a relação entre religião e violência? Alguns autores irão argumentar que a religião pode ser uma solução para aspectos ligados a uma violência social ou mesmo da natureza humana; enquanto outros autores irão dizer o contrário, que a religião pode ser uma variável que devemos observar, uma vez que ela pode produzir conflito e gerar violência através de uma lógica própria. Então, como o senhor colocaria esse debate sobre a relação entre religião e violência? Ela justifica a violência às vezes ou é um instrumento para frear alguns tipos de violência? Como o senhor enxerga isso?

\section{TV}

Bem, declaro minha absoluta ignorância no tema. Portanto só me permito algumas observações que podem resultar do conhecimento de elementos de história ou de discussões sobre moral ou mesmo sobre religião. 0 tema tem sido muito discutido, muitos falam sobre o assunto. Mas buscar na religião, ainda que parcialmente, explicações para 
a violência não me parece justo. Ainda que a religião, de fato, tenha sido, digamos assim, uma justificação ideológica da violência ao longo da História: as Cruzadas, os massacres de povos indígenas. Nesses casos, por se tratar de fatos longínquos, é mais fácil, hoje, buscar objetividade e verificar os interesses.

Um exemplo para evitar os riscos do circunstancial e conjuntural. Na Idade Média, algumas ordens cristãs, os jesuítas e os dominicanos, em alguns casos usaram intensamente a violência para extorquir diversos tipos de atitudes das populações que não se sujeitavam plenamente à sua própria dominação, seja material, seja moral ou religiosa. Inclusive com torturas. A Inquisição é o exemplo mais conhecido. Mas qual era a razão? A razão imediata era lutar contra os infiéis. Para eles, infiéis eram os muçulmanos, os judeus, os pagãos, os indígenas, as bruxas etc. Depois, incluíram também os protestantes ou outros. Entretanto, a razão de fundo era a manutenção da dominação de determinados setores. De modo que algumas ordens usavam esses instrumentos para servir aos soberanos das diferentes regiões, particularmente na Espanha isso foi muito visível. Usou-se a violência, a tortura, o extermínio com o argumento religioso da pureza da fé. Hoje, com a distância que nos permite o tempo, diagnosticamos o objetivo da manutenção do próprio poder. 0 que não invalida a ideia de que havia pessoas que acreditassem nos argumentos. Voltando às questões contemporâneas, as religiões podem ser instrumentalizadas, e provavelmente o sejam em alguns casos, mas não diria que a essência das religiões - de qualquer religião atualmente existente no mundo - possa ser identificada como, em si mesma, origem da violência.

\section{RM}

Então, talvez, digamos assim, um mundo altamente religioso não seja necessariamente um mundo mais violento, nem mais pacífico. Assim como um mundo totalmente laico não seria um mundo nem mais nem menos pacífico.

\section{TV}

Não há superposição. Absolutamente, é exatamente esta a ideia.

\section{RM}

Tullo, vamos entrar um pouco mais especificamente no Oriente Médio como tema da discussão. Quando se fala em Oriente Médio, isso já é um conceito que traz uma bagagem importante para entender o que estamos falando. E isso em boa medida se relaciona a uma discussão geopolítica. Então o Oriente médio se insere numa visão de mapa e de organização do mundo. E essa visão mais relacionada com questões de território, com questões de área de influência, nos leva a um campo de estudo muito tradicional, que é a geopolítica. Muitos autores vão enfatizar que a geopolítica é uma variável muito importante para explicar a violência no Oriente Médio. Como o senhor relaciona a geopolítica com a violência no Oriente Médio? 


\section{entrevista}

\section{TV}

Mais uma vez retomo a ideia que cada caso é um caso e há muitas especificidades, cada região, cada grupo étnico, cada país, cada Estado possui suas especificidades. A geopolítica tem muita importância na explicação das complexidades do Oriente Médio, por várias razões. A principal é que esta região toda, certamente como outras (a África e grandes partes da Ásia), foi totalmente colonizada, de forma direta ou não, pelas potências europeias, desde o século XVIII, com forte intensidade no XIX. Fala-se muito na França e na Grã-Bretanha, antes no Império Otomano, mas também Holanda, Bélgica, Itália, Alemanha, Espanha e Portugal. Todos esses países tiveram peso na colonização dessas regiões. 0 colonialismo exercido por esses países produziu graves dificuldades para o equilíbrio social, econômico, cultural e político nesta região: vejam que me refiro ao equilíbrio. 0 que não é sinônimo de desenvolvimento ou crescimento. 0 colonialismo (ou neocolonialismo) teve papel na atomização, na definição ou redefinição de fronteiras. Basta ver as fronteiras no Oriente Médio, são linhas traçadas com a régua - ao menos uma parte delas - e as próprias populações divididas entre vários Estados, vejamos o caso dos curdos, mesmo o caso dos armênios, e outros. 0 mesmo pode-se dizer em relação a outros grupos como os drusos e os beduínos. 0 mesmo vale para as divisões étnico-culturais, intrareligiosas, como xiitas e sunitas. Diferente é o caso do Líbano, onde durante séculos a convivência entre cristãos e muçulmanos alcançou grande equilíbrio. Quais são as consequências dos graves desequilíbrios produzidos? São evidentes: dificuldades crescentes. A capacidade das elites de cada país para reagir e superar essas condições foi muito diferente. No caso dos Oriente Médio e Próximo, às condições gerais soma-se o papel estratégico que a partir do final do Século XIX representou Suez e, logo em seguida, o petróleo, sobretudo o do Golfo Pérsico. As intervenções externas mais significativas relacionam-se a isso: Mossadegh, Nasser.

A geopolítica e as políticas imperiais, sobretudo, dos países da Europa - e, a partir da segunda metade do séc. XX, também os Estados Unidos e em menor grau a União Soviética/y - tiveram o papel de cortar a possibilidade de manutenção do equilíbrio nessas regiões. As consequências subsistem até hoje e explicam muito. Reiterando, não é um problema específico do Oriente Médio. Os problemas e as dificuldades no surgimento de elites modernizadoras e competentes são problemas mais amplos, em algum modo atinge, mesmo que de forma muito dispare, como sabemos, com respostas e capacidades totalmente diferentes, todos os países que sofreram o colonialismo.

\section{RM}

Bom, Tullo, o senhor mencionou o histórico da colonização, esse processo da História que nos ajuda a entender a formação dos territórios e as dificuldades que isso produz. Mas será, também, que esse argumento histórico não é usado para justificar alguns conflitos e como instrumento para justificativa de ações violentas? A História não é, muitas vezes, usada até de forma caricata para justificar ações violentas ou revoluções? 


\section{TV}

Sim, ela pode ser utilizada. Dei um exemplo definitivo para explicar isso. É possível explicar o Nazismo pelas injustiças que os alemães sofreram, particularmente em vista das imposições resultantes dos acordos de Paz resultantes da Primeira Guerra Mundial. Mas, isso justifica o Nazismo? Absolutamente não. Mas digamos, é uma vertente explicativa. Todos os fenômenos têm uma explicação. 0 que inclui aspectos valorativos, psicológicos, percepções etc. Não se pode atribuir a violência a uma percepção inerente a determinadas sociedades, que produziriam determinados resultados. Lembrando Locke, as sensações humanas são determinadas pelas impressões empiricamente adquiridas e não da existência de ideias, valores, conhecimentos inatos, de um fundamento inteligível pré-existente. As sociedades, as culturas, as famílias, as religiões reproduzem valores. Mas eles têm uma base. Os resultados estão sempre ligados a explicações que têm que ser compreendidas em sua profundidade. Isso permite chegar num ponto sobre o qual é muito importante insistir. Em qualquer tipo de conflito a política é a arte da capacidade de negociação.

O que causa perplexidade enorme em qualquer tipo de conflito - não me refiro somente aos conflitos do Oriente Médio, podem ser conflitos nacionais, internos - é a fuga da política. A política é o campo da negociação. Para quem quer resolver qualquer tema, qualquer questão, o único caminho possível é manter-se dentro da política. Manter-se dentro da política significa reconhecer o adversário, não desqualificá-lo. Adler (Emmanuel), dizia que no caso do Oriente Médio - particularmente no caso do conflito Israel-Palestina - prevalecem lógicas de tipo pré-político e não lógicas da política. Atentados, violência, massacres, atos todos condenáveis, que devem ser impedidos e contidos, refletem acúmulo histórico de injustiças e a percepção de que essas injustiças perduram ao longo tempo. Os atos condenáveis espelham a recusa, que também tem motivações e devem ser compreendidas nas suas razões, de ingressar no campo da política, no campo da negociação.

Por isso a necessidade da comparação entre democracia representativa (que para os liberais é a mais pertinente) e sistema de democracia direta. A democracia direta é a manifestação direta dos interesses, por isso, muitas vezes, a esquerda entende que este tipo é o mais democrático. Porque manifestam-se de forma direta os interesses, sem mediações. Pode levar ao choque e ao enfrentamento. No caso da democracia representativa, esta tem por natureza o diálogo e a negociação. Por isso, os representantes parlamentares têm em princípio a tendência a serem mais aptos ao diálogo com opositores, adversários ou até inimigos. 0 fato de que isso nem sempre aconteça, não invalida o conceito. Em todos os casos, o espaço do diálogo e da política é o que pode produzir resultados efetivos. Se não há este espaço, ou se a negociação é utilizada apenas como instrumento para a obtenção de resultados absolutos, se inviabiliza a política. Às vezes, nestas questões quem age de forma mais violenta o faz na crença de que não há outra possibilidade para alcançar seus objetivos. É nesse sentido que deve ser compreendida a afirmação de Clausewitz, a guerra é 
uma parte da política e a violência também o é. Para ele, o valor que prevalece é a política. Muitas ações de violência estão conectadas a objetivos políticos. Aron (Raymond) entende que a paz é um intervalo entre guerras. 0 pressuposto de que o estado natural dos povos é a guerra origina-se na ideia westfaliana da soberania e da anarquia internacional. Toda a evolução política e institucional, com desdobramentos fortes no Direito Internacional Público, ao longo do século XX e agora no XXI, deveria reforçar o valor e a capacidade real da política em oferecer garantias. Há ainda significativa debilidade do campo da política, o uso das diferentes formas de força, seja a guerra, sejam outras, é o perdurar de temas não adequadamente resolvidos.

\section{RM}

Esta perspectiva fica bastante clara quando o Estado Islâmico declara, por exemplo, que irá abolir as fronteiras do acordo de Sykes-Picot, que foi seguido em linhas gerais pelo Mandato Francês em sua delimitação das fronteiras na região.

\section{TV}

Em 2016 comemoram-se os 100 anos do acordo. Trata-se de uma ocasião, como tem sido, para pesquisar qual sua real importância. Foi um acordo, quase informal, concluído por dois diplomatas, britânico e francês, para desenhar as zonas de influência no Oriente Médio. Essas zonas e parte dos limites dos Estados foram desenhados por esse acordo, particularmente as de Jordânia, Iraque, Líbano e Síria. Tampouco pode ser superestimado. É muito lembrado, assim como a Declaração de Balfour, de 1917, porque os acontecimentos regionais sucessivos tiveram desdobramentos que levaram à implementação de parte de seus pressupostos. As potências europeias e as elites árabes respeitaram parte das diretrizes de Sykes-Picot por servirem à consolidação de seus interesses.

\section{RM}

Nesse sentido, nós tínhamos três agendas naquele momento para a região: uma agenda seria o tratado de Sykes-Picot; a outra seria o tratado de Balfour e sua promessa de um lar judaico na Palestina; e uma terceira agenda seria a promessa de Grande Arábia ao Sherif Hussein de Meca - que foi precisamente o projeto que o Sykes-Picot e Balfour trairiam. Portanto eu pergunto: é possível argumentar que o Oriente Médio seja vítima deste imperialismo ocidental? Ou isso é uma análise muito rasa, ou, talvez, uma análise cruamente marxista e existem outros elementos que deveríamos adicionar à análise? Quer seja falar em uma dificuldade religiosa endêmica, quer seja falar de uma dificuldade societária de entrar em acordo. Complementando isso, hoje temos os intelectuais se posicionando de maneira polarizada nesse sentido. De um lado os intelectuais neomarxistas, muito alinhados aos intelectuais mais relativistas dizem que o Oriente Médio é fruto deste processo histórico colonialista e isso está em boa medida no cerne das razões para a violência atual. 
E qualquer violação de direitos humanos deve ser de alguma forma respeitada, por que aquilo tem a ver com o relativismo cultural e com práticas muito específicas, devendo ser tomado com bastante cuidado. E a outra linha, seria, por exemplo, os intelectuais mais liberais que falam de uma paz democrática, argumentando que se esses países fossem efetivamente mais democráticos e liberais a guerra não ocorreria. E aí podemos falar em exportação de democracia, de aumento de Direitos Humanos. Aqui faço a referência a um texto do próprio Peter Demant que tenta enquadrar os intelectuais neste debate sobre o Oriente Médio e sobre o terrorismo.

\section{TV}

Tenho muitas dúvidas sobre as duas opções intelectuais que vocês apontam. Explicar o Oriente Médio como resultado linear da ação do imperialismo ocidental mais do que raso, é errado. Seria desconhecer o papel das elites dos diferentes países, a estrutura social e econômica, o papel dos valores etc. Do mesmo modo, explicar pelas dificuldades religiosas é muito restritivo. Como já disse, a atribuição aos povos e às pessoas de características inatas, imutáveis, é uma ideia absurdamente a-histórica. No campo da Teoria das Relações Internacionais há intenso debate sobre quais são as motivações da paz. A contribuição neokantiana de Doyle (Michael) sobre a ideia de Paz Democrática é relevante. Autores importantes, como Przewosrski (Adam), buscam estabelecer correlação entre democracia e aptidão à paz. Na verdade, essa correlação é difícil de ser estabelecida. Przeworski argumenta que há uma certa correlação, ainda que não total. A forma como se estabelecem as correspondências deve ser levada em conta. Na história contemporânea, de 1990 à atualidade, grande parte dos conflitos não foram inter-estatais, ou quando o foram tiveram intensidade relativamente baixa: como contabilizá-los? Na Primeira Guerra Mundial as alianças não foram estabelecidas entre regimes autoritários de um lado e regimes democráticos do outro. A Alemanha era um Estado democrático, assim como a França, e os dois entraram em guerra. No contexto europeu do período, um Estado autoritário, ou semi-autoritário, era a Rússia e a Rússia foi aliada de países democráticos. Portanto, interpretar o Oriente Médio, por um lado, como vítima do imperialismo ou, por outro, como resultado de dificuldades societárias, mesmo ambos contendo verdades parciais, parecem ideias reducionistas, simplificadoras.

\section{RM}

E também se há uma correlação, também ela não explica o elemento de causalidade, não é?

\section{TV}

Sim, não explica o elemento de causalidade. Como estabelecer isso no Oriente Médio? Por exemplo, se há um país do Oriente Médio reconhecidamente autocrático é a Arábia Saudita, mas a Arábia Saudita não tem participado ativamente de guerras, ao menos de 
guerras formais. É uma potência militar muito importante no Oriente Médio, mas não participou ou não causou diretamente guerras importantes na região nos últimos 60 anos. Quem participou de guerras plenas foram Síria, Israel, Jordânia, Iraque e também o Irã. Outros países árabes não participaram, como Tunísia, Argélia, Marrocos. 0 Egito sim, até 1973, mas depois não mais participou de guerras, apesar de seu ativismo militar.

\section{RM}

Tullo, o debate sobre os Direitos Humanos é importante porque, muitas vezes, intelectuais fazem críticas ao Islã e aos Estados do mundo muçulmano, justamente enfatizando essa questão das violações dos Direitos Humanos. Outros autores são mais relativistas e afirmam que pela estruturação social e por razoes sociais , religiosas, culturais ou históricas algumas violências se manifestam nestes locais. Dessa forma, para esses autores, falar em DH no Oriente Médio e no Mundo Muçulmano é uma forma de ataque, de ignorância ou de autores mal-intencionados. Como o senhor pensa e avalia esse debate?

\section{TV}

Sobre o tema de Direitos Humanos, há muitos pesquisadores e intelectuais, inclusive no Brasil, que vem estudando essa questão. Um dos autores que vem escrevendo a esse respeito é o embaixador Lindgren Alves. Inclusive aqui no Instituto de Ciência e Tecnologia de Estudos sobre os Estados Unidos (INCT-INEU) há estudos importantes a respeito, particularmente do ponto de vista das relações internacionais, com foco nas políticas dos Estados Unidos, como os de Andrei Koerner, Marrielle Maia, Glenda Mezarobba, Debora Maciel entre outros. Não sou especialista no tema, não posso dizer nada definitivo. 0 tema dos Direitos é secular: incluindo temas morais, filosóficos, sociológicos, de gênero e outros. 0 risco é cair em formas universalistas que não se sustentam, ou, inversamente, aceitar relativismos ou pós-modernismos sem sentido. Também esse confronto tem sido e continua intenso e está longe de se resolver. 0 debate sobre o relativismo em Direitos Humanos ocorreu na Conferência das Nações Unidas sobre os Direitos Humanos, em Genebra em 1993. Em relação a esse tema podemos retomar o que já foi dito: sua formulação, sua mobilização corresponde também a interesses, a concepções de mundo a que estão ligados. A conferência das Nações Unidas reconheceu essas diferenças, mas também estabeleceu que há um núcleo comum de Direitos Humanos que é válido para todas as civilizações. São direitos milenares, ainda que muitas vezes não respeitados: direito à vida, a pensar livremente, ao bem estar, etc..

Respondendo à pergunta, atribuir ao Islã uma aptidão maior para estabelecer limites e restrições aos DH não parece responder à verdade histórica. Limites ao papel da mulher existem entre os cristãos, entre os judeus. Por outro lado, há Estados muçulmanos e árabes onde prevalece grande liberdade laica, como no Marrocos ou na Tunísia. 0 que podemos concluir é que a questão dos direitos existe sim, mas não é geneticamente diferente dos 
limites existentes em outras sociedades e em outras culturas. A instrumentalização de certos valores, mesmo religiosos, corresponde a interesses de grupos, de elites, muitas vezes é utilizada como fator de coesão social, ainda que consentida.

\section{RM}

Passando agora para algumas questões mais específicas de conjuntura, o acordo nuclear entre Irã e Estados Unidos está prestes a completar um ano e o debate é ainda aberto. Alguns analistas afirmam que o acordo foi benéfico, e que o Irã é um ator estável e responsável; enquanto outros afirmam que o Irã não necessariamente vem cumprindo o prometido e o país vem se tornando uma ameaça crescente no Oriente Médio. Qual sua avaliação sobre este acordo Estados Unidos-Irã?

\section{TV}

Ressalvando meu desconhecimento sobre as especificidades do acordo e sobre sua implementação, do ponto de vista das Relações Internacionais, isto é, do ponto de vista político, o acordo parece ser positivo. Como vim expondo nesta entrevista, o fortalecimento do campo da política é sempre positivo. Negociar acordos é importante para preservação não somente da paz, mas também dos direitos. Paz sem direitos cria pressupostos para rompimento da mesma em fases sucessivas. Pelo que é de conhecimento público, os países promotores do acordo detém meios para avaliação da compliance, inclusive meios corretivos se necessário.

\section{RM}

Agora um Irã, digamos assim, mais fortalecido nas relações regionais, isso é interessante em termos de política internacional ou ele seria mais uma ameaça?

\section{TV}

Países insatisfeitos representaram ao longo da história um grave risco para a paz e a segurança. O Irã é um país com uma cultura e com um desenvolvimento social e tecnológico importante. 0 fato não é novo, buscou sempre, inclusive no período do Xá Rezha Pavlevi, modernizar-se. A República Islâmica manteve o desenvolvimento tecnológico, há uma elite intelectual preparada. O International Institute for Strategic Studies (IISS) de Estocolmo informa que hoje aproximadamente 35 países têm a capacitação tecnológica para produzir armas nucleares. Não as possuem, mas há a potencialidade de produzi-las de forma rápida, têm a tecnologia.

Há um outro problema, que se refere ao fato de apenas alguns Estados manterem as armas nucleares. Waltz (Kenneth), em artigo de 2012 afirma que a contenção da expansão da tecnologia nuclear não necessariamente é uma garantia para evitar perigos maiores ${ }^{2}$. No

\footnotetext{
2 "Why Iran Should Get the Bomb" Foreign Affairs, July/August 2012.
} 


\section{entrevista}

fundo, ele trabalha com o que é próprio de sua obra, o equilíbrio. Para ele, evitar os riscos nucleares implica ter maior número de atores com armas nucleares para manter um equilíbrio no jogo. Sem necessariamente compartilhar a totalidade da análise, de qualquer forma, no caso do Irã, o acordo impede a produção de armas nucleares a curto prazo, a longo prazo dependerá de nova geração de acordos. 0 Acordo conferiu a possibilidade ao país de manter-se com um desenvolvimento tecnológico compatível com seus interessesainda que proibida a produção 7 de armas nucleares - e está viabilizando o retorno do Irã à comunidade internacional do ponto de vista comercial, financeiro, tecnológico, de comunicações, de viagens etc. Nesse sentido, o acordo, em princípio, é favorável e dentro destas circunstâncias - como o Irã está sendo decididamente monitorado pelos seis países que assinaram o acordo e pela Agência Internacional de Energia Atômica o fato do Irã permanecer como um país militarmente significativo na região não é um elemento negativo. De distintos pontos de vista, realista, liberal, institucionalista, poderá ser induzido a um jogo de equilíbrios, incluindo Turquia, Arábia Saudita, Egito e Israel, além de Estados Unidos e Rússia.

\section{RM}

Tullo, ainda nessa discussão de conjuntura, um outro dado político que é muito complicado é o crescimento da extrema direita na Europa. A extrema direita, no espectro político, sempre existiu com características que refletem o momento histórico. E, no momento atual, ela tem essa característica muito ligada à xenofobia, ao sentimento anti-estrangeiro, mas, também, com uma forte mensagem anti-Islã: a islamofobia. Como o senhor avalia esse movimento de crescimento da extrema direita com uma retórica islamofóbica?

\section{TV}

Qualquer pessoa com visão democrática vê com extrema preocupação esse tipo de atitude. Os Estados deveriam ter instrumentos para combater esse fenômeno que é antigo, mas se apresenta como novo. Como alguns resultados eleitorais têm demonstrado, votações para determinados partidos políticos, na Áustria, por exemplo, mesmo na Itália, os resultados do referendo na Inglaterra, evidenciam que sentimentos de xenofobia, particularistas, anti-modernização, vem se multiplicando por diferentes razões. Há sentimentos de preservação de privilégios, há sentimentos tradicionalistas, que originam a xenofobia e o racismo. Há a busca de preservação de identidades, a busca de se contrapor a outros grupos étnicos, nacionais, culturais, religiosos. Tudo isso estimulado por forças que buscam a instrumentalização para fortalecer-se social e eleitoralmente. 0 combate a essas tendências não pode ser feito só com base na tentativa de convencer intelectual e

Waltz era um defensor da tese de que quanto mais armas nucleares no mundo, maior o equilíbrio de poder e a paz global, haja vista que os países analisam melhor as consequências de um ataque militar de seus adversários No mesmo sentido, "The Spread of nuclear Weapons: More May Be Better" The Adelphi Papers, Volume 21, Issue 171, 1981. [Nota do entrevistador]. 


\section{entrevista}

culturalmente de que a xenofobia é um sentimento moralmente negativo.

Trata-se de debate de grande envergadura. Sobretudo, seria necessário um debate mundial, nacional e em cada lugar sobre as razões das grandes e descontroladas migrações. Esse tema relaciona-se diretamente com o eixo dessa entrevista, as responsabilidades históricas, a pobreza, a eliminação de estruturas sociais e sistemas de proteção em muitos países, etc.. Combinando esse debate com as consequências do desenvolvimento científico e tecnológico, com a distribuição crescentemente assimétrica dos benefícios. Se determinados grupos sociais são marginalizados, se aumenta o seu nível de pobreza e se sentem excluídos dos benefícios da globalização e da modernização da economia. Não resolvidos os temas de fundo, os riscos de aumento do racismo são grandes. Algumas das forças genericamente chamadas xenófobas não possuem ainda viés autoritário, podem ser confundidas com a chamada onda anti-política que parece existir em países ricos e em pobres.

\section{RM}

Tullo, ao longo da entrevista você enfatizou a importância do entendimento através da política, da negociação e do diálogo, ao mesmo tempo em que se presta atenção nos processos históricos e nas injustiças, além das especificidades de cada conjuntura. Mas se fossemos pensar em soluções para estes problemas, qual seria sua percepção para lidar com o terrorismo, com a violência relacionada à religião (contra ou através dela), com o combate ao DAESH/Estado Islâmico e com esta trama de conflitos contemporâneos?

\section{TV}

Repetindo o que disse, a solução deve ser dada pela prevalência da política e pela compreensão do outro, é a compreensão das razões do outro, mesmo que este outro desenvolva ações que vão contra nossos próprios interesses. É importante compreender as razões dos outros para avançarmos. Uma lembrança: falamos de algumas das razões que levaram à Segunda Guerra Mundial. Um dos pontos importantes acertados entre Roosevelt, Churchill e Stalin durante a Segunda Guerra Mundial foi de que alguns dos erros dos anos 1920 não deveriam repetir-se: repartições coloniais, reparações, acordos secretos. De fato, esses erros não se repetiram. Não se trata de uma visão simplista e idealista. Problemas atuais, terrorismo, violações de direitos humanos, guerras devem ser compreendidos em suas razões. Buscando ao menos a compreensão de suas causas, das razões do outro. Não resolve, mas é um ponto de partida.

\section{RM}

Mesmo que este outro seja um fundamentalista ou um fanático? Outra coisa que é fundamental é reconhecer a racionalidade dessas estratégias e destes atores. A extrema direita pode ser fundamentalista porque antissemita e xenófoba, mas tem suas razões materiais e estruturais de ser, pois responde a vácuos ideológicos e identitários, a 
problemas de burocracias do establishment e a mazelas econômicas. 0 mesmo vale para um fundamentalista religioso.

\section{TV}

A definição de fundamentalista é complexa. Mesmo um fundamentalista, é um ator. Esta é a lógica da política, é entender quais são suas razões, e não há como evitar isto. A alternativa seria o aniquilamento dos opositores, uma visão também presente na política, como na obra de Schmitt (Carl), mas produzirá resultado posterior indesejado. Quase qualquer movimento revolucionário, anarquistas espanhóis ou anarquistas sérvios, podem ser classificados como terroristas. Hoje, separar estas figuras de suas razões políticas seria difícil. Não se considera os anarquistas espanhóis como terroristas atualmente, e atitudes como o assassinato do arquiduque Francisco Fernando em 1914 em Sarajevo são hoje consideradas como parte da história europeia.

Portanto entender o outro é o grande problema contemporâneo. 